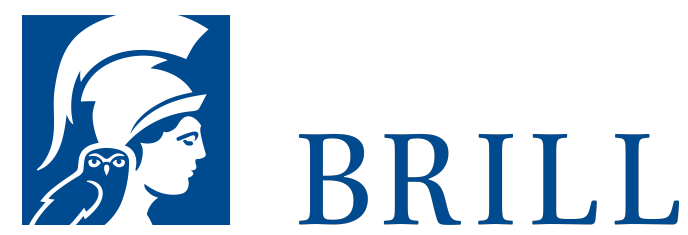

\title{
Der Mythos des Singulären
}

Eine Untersuchung zur Struktur kollektiven Handelns

Author: David P. Schweikard

Gemeinsame Aktivitäten, von spontanem Kooperieren von zwei Akteuren bis zum Handeln in oder von in komplexer Weise organisierten Kollektiven, gehören zu den Grundphänomenen des alltäglichen menschlichen Lebens. Diese Untersuchung ist den zentralen handlungstheoretischen und sozialontologischen Problemen gewidmet, die diese Phänomene aufwerfen. Es wird unter Rekurs auf neuere Literatur zu kollektiver Intentionalität und Sozialontologie ein systematischer Vorschlag zur Individuation kollektiver Handlungen, zur Intentionalität gemeinsamen Handelns und zur Akteurschaft von Kollektiven entwickelt. Die Hauptthese dieses Vorschlags ist kritisch gegen Spielarten reduktionistischer und individualistischer Analysen gewendet und besagt, dass kollektives Handeln nur dann adäquat analysiert werden kann, wenn die Vorstellung, es sei durch Zusammensetzungen aus für sich vollständig bestimmten individuellen Handlungen und Absichten gekennzeichnet, aufgegeben wird. Im Einzelnen wird für eine nicht-reduktive Analyse gemeinsamer Handlungsabsichten sowie für die Auffassung argumentiert, dass bestimmte Kollektive eine Art interner Struktur aufweisen, die ihre Anerkennung als Akteure rechtfertigt.

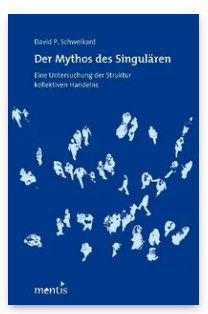

Pages: 463

Seiten

Language:

German

Subjects: 19th \& 2oth Century

Philosophy, Philosophy

Publisher: Brill | mentis

E-Book (PDF)

Released online:

o1 May 2011

ISBN: 978-3-

95743-882-9

List price

USD $\$ 75.00$

Paperback

Publication date:

o1 May 2011

ISBN: 978-3-

89785-721-6

List price

USD $\$ 75.00$ 
For more information see brill.com

Order information: Order online at brill.com +44330 333 0049 | customerservices@brill.com Submission information: brill.com/authors

Titles published by Brill | Fink, Brill | mentis or Brill | Schöningh: +49(o)715413279216| brill@brocom.de 